\title{
GAMBARAN SARANA SANITASI DASAR DI DUSUN LEMBANG DESA BONTO BIRAENG KECAMATAN KAJANG KABUPATEN BULUKUMBA
}

\author{
Misrah dan Mulyadi \\ (misrahira181@gmail.com,085340736723)
}

\begin{abstract}
the condition of poor sanitation facilities can affect health. These sanitation facilities can be seen around the home environment, such as clean water, family latrines, waste water disposal, and garbage disposal. These sanitation facilities must be considered to prevent contamination and to prevent the proliferation of vector vectors. The purpose of this research is to find out the description of sanitation facilities in Lembang Hamlet, Bonto Biraeng Village, Kajang District, Bulukumba Regency. ". This type of research is observation with a descriptive approach or survey to the field using a questionnaire. The samples in the study were 132 families taken randomly. The results of this study indicate that the condition of clean water facilities is 132 houses (100\%) that meet the requirements of 97 houses $(73.5 \%)$ and those that do not meet the requirements of 35 houses $(26.5 \%)$, toilet facilities for 132 families (100\%) who meet the requirements of 110 houses $(83.3 \%)$ and those that do not meet the requirements of 22 houses $(16.7 \%)$, waste water disposal facilities that have 0 houses $(0 \%)$ that do not have 132 houses $(100 \%)$, which fulfilled the requirements of 0 houses (0\%), and did not meet the 132 house requirements (100\%) and garbage disposal facilities that had 132 houses (100\%) that met the requirements of 0 houses (100\%) and those that did not fulfill 132 houses (100\%).As a conclusion from the research that the environmental sanitation factor is very influential on the condition of settlements because the condition of unhealthy environmental sanitation can cause disease and if the conditions of environmental sanitation facilities that meet the requirements can increase community health status.
\end{abstract}

Keywords: Basic Sanitation Facilities, Environment, Hous

\section{ABSTRAK}

Kondisi sarana sanitasi yang buruk dapat mempengaruhi kesehatan.sarana sanitasi tersebut dapat di lihat di sekitar lingkungan rumah, seperti air bersih, jamban keluarga, pembuangan air limbah, dan pembuangan sampah. Sarana sanitasi tersebut harus diperhatikan untuk mencegah timbulnya kontaminasi dan untuk mencegah terjadinya perkembangbiakan vektor penyakit. Tujuan dari penelitian ini untuk mengetahui gambaran sarana sanitasi dasar di Dusun Lembang Desa Bonto Biraeng Kecamatan Kajang Kabupaten Bulukumba. Jenis penelitian ini adalah observasi dengan pendekatan deskriptif atau survai ke lapangan dengan menggunakan kuesioner. Sampel dalam penelitian ini sebanyak $132 \mathrm{KK}$ di ambil secara random sampling. Hasil penelitian ini menunjukkan kondisi sarana air bersih yang ada 132 rumah $(100 \%)$ yang memenuhi syarat 97 rumah $(73,5 \%)$ dan yang tidak memenuhi syarat 35 rumah $(26,5 \%)$, sarana jamban keluarga yang ada 132 rumah $(100 \%)$ yang memenuhi syarat 110 rumah $(83,3 \%)$ dan yang tidak memenuhi syarat 22 rumah (16,7\%), sarana pembuangan air limbah yang ada 0 rumah (100\%) dan tidak memiliki 132 rumah (100\%), yang memenuhi syarat 0 rumah (0\%), dan tidak memenuhi syarat 132 rumah (100\%) dan sarana pembuangan sampah yang ada 132 rumah (100\%) yang memenuhi syarat 0 rumah (100\%) dan yang tidak memenuhi syarat 132 rumah (100). Sebagai kesimpulan dari penelitian bahwa faktor sanitasi lingkungan sangat berpengaruh pada kondisi permukiman karena kondisi sanitasi lingkungan yang kurang sehat dapat menimbulkan penyakit dan apabila kondisi sarana sanitasi lingkungan yang memenuhi syarat maka dapat mempertinggi derajat kesehatan masyarakat.

Kata kunci : Sarana Sanitasi Dasar, Lingkungan, Rumah

\section{PENDAHULUAN}

Menurut World Healt Organization

(WHO) sanitasi adalah penyediaan sarana dan pelayanan pembuangan limbah kotoran manusia seperti urin dan feces. Istilah "sanitasi" juga mengacu kepada pemeliharaan kondisi higienis melalui upaya pengelolaan sampah dan pengelolaan limbah cair. Sanitasi di artikan sebagai alat pengumpulan dan pembuangan tinja serta air buangan masyarakat secara higienis sehingga tidak membahayakan bagi kesehatan seseorang maupun masyarakat secara keseluruhan. Kesehatan diarahkan untuk meningkatkan kualitas sumber daya manusia, meningkatkan kesejahteraan manusia serta untuk mempertinggi kesadaran masyarakat akan pentingnya hidup sehat. Sarana dan kebijakan pembangunan perumahan dewasa ini dirasakan pada golongan masyarakat yang berpenghasilan rendah, daerah kumuh, perkotaan, daerah pedesaan ddan daerah terpencil.

Sanitasi adalah perilaku di sengaja dalam pembudayaan hidup bersih dengan maksud mencegah manusia bersentuhan langsung dengan kotoran dan bahan buangan berbahaya lainnya dengan harapan usaha ini akan menjaga dan meningkatkan kesehatan manusia.

Menurut WHO permukiman adalah "suatu struktur fisik" dimana orang menggunakannya untuk tempat berlindung, dimana lingkungan dari struktur tersebut termasuk juga semua fasilitas dan pelayanan yang diperlukan, perlengkapan yang berguna untuk kesehatan jasmani dan rokhani, dan keadaan sosialnya yang baik untuk keluarga dan individu. Sanitasi lingkungan adalah status 
Jurnal Sulolipu : Media Komunikasi Sivitas Akademika dan Masyarakat

Vol. 19 No.2 2019

e-issn : 2622-6960, p-issn : 0854-624X

kesehatan suatu lingkungan yang mencakup perumahan, pembuangan kotoran, penyediaan air bersih dan sebagainya (Notoatmodjo, 2003).

\section{METODE}

\section{Desain, Tempat Dan Waktu}

Variabel bebas adalah variabel yang di duga berpengaruh terhadap variabel terikat dalam hal ini gambaran sanitasi lingkungan yang meliputi penyediaan air bersih, jamban keluarga, pembuangan air limbah, dan pembuangan air limbah. Variabel terikat adalah variabel yang dipengaruhi oleh variabel bebas. Lokasi penelitian dilaksanakan di Dusun Lembang Desa Bonto Biraeng Kecamatan Kajang Kabupaten Bulukumba. Waktu pelaksanaan pada bulan Maret s/d Juni 2019.

\section{Populasi Dan Sampel}

Populasi dalam penelitian ini adalah seluruh kepala keluarga yang berada di Dusun Lembang Desa Bonto Biraeng Kecamatan Kajang Kabupaten Bulukumba sebanyak 197 KK. Dan Sampel yang diambil dalam penelitian ini adalah sebanyak $132 \mathrm{KK}$.

\section{Pengumpulan Data}

Dalam penelitian ini teknik pengumpulan data yang diambil adalah observasi dan checklist.

\section{Pengolahan Data}

Pengolahan data yang digunakan pada penelitian ini adalah dengan cara komputerisasi dan alat bantu hitung (kalkulator).

\section{Analisa Data}

Analisa data dilakukan setelah data di dapat dan diolah, maka selanjutnya data diolah dengan cara deskriptif yang berdasarkan persentase (\%).

\section{Hasil}

Berdasarkan penelitian yang telah dilakukan di Dusun Lembang Desa bonto Biraeng Kecamatan Kajang Kabupaten Bulukumba pada bulan april mengenai gambaran sarana sanitasi dasar. Dengan sampel sebanyak $132 \mathrm{KK}$. Maka hasil penelitian yang diperoleh dapat di sajikan dalam tabulasi data sebagai berikut:
Tabel 1

Distribusi jenis sarana penyediaan air bersih di Dusun Lembang Desa Bonto Biraeng Kecamatan Kajang Kabupaten Bulukumba Tahun 2019

\begin{tabular}{|c|c|c|c|}
\hline No & Jenis Sarana & Jumlah & $\%$ \\
\hline 1 & SGL & 131 & 99,2 \\
\hline 2 & S.BOR & 1 & 0,8 \\
\hline 3 & PAH & - & - \\
\hline & & 132 & 100 \\
\hline
\end{tabular}

Tabel 2

Distribusi kepemilikan sarana air bersih di Dusun Lembang Desa Bonto Biraeng Kecamatan Kajang Kabupaten Bulukumba Tahun 2019

\begin{tabular}{|c|c|c|c|}
\hline No & Kepemilikan & Jumlah & $\%$ \\
\hline 1 & Sendiri & 112 & 84,8 \\
\hline 2 & Tetangga & 20 & 15,2 \\
\hline & Total & 132 & 100 \\
\hline
\end{tabular}

Tabel 3

Distribusi kondisi sarana penyediaan air bersih di Dusun Lembang Desa Bonto Biraeng Kecamatan Kajang Kabupaten Bulukumba Tahun 2019

\begin{tabular}{|c|c|c|c|}
\hline No & Jarak & Jumlah & $\%$ \\
\hline 1 & $>11$ meter & 127 & 96,2 \\
\hline 2 & $<11$ meter & 5 & 3,8 \\
\hline & Total & 132 & 100 \\
\hline
\end{tabular}


Jurnal Sulolipu : Media Komunikasi Sivitas Akademika dan Masyarakat

Vol. 19 No.2 2019

e-issn : 2622-6960, p-issn : 0854-624X

Tabel 4

Distribusi jenis sarana jamban keluarga di Dusun Lembang Desa Bonto Biraeng Kecamatan Kajang Kabupaten Bulukumba Tahun 2019

\begin{tabular}{|c|c|c|c|}
\hline No & Jenis & Jumlah & $\%$ \\
\hline 1 & Leher angsa & 110 & 83,3 \\
\hline 2 & Cemplung & 22 & 16,7 \\
\hline & & & \\
\hline & Total & 132 & 100 \\
\hline
\end{tabular}

Tabel 5

Distribusi kepemilikan sarana jamban keluarga di Dusun Lembang Desa Bonto Biraeng Kecamatan Kajang Kabupaten Bulukumba Tahun 2019

\begin{tabular}{|c|c|c|c|}
\hline No & Kepenmillkan & Jumlah & $\%$ \\
\hline 1 & Sendill & 132 & 100 \\
\hline 2 & Telanoga & $\cdot$ & $\cdot$ \\
\hline 3 & Toial & 132 & 100 \\
\hline
\end{tabular}

Tabel 6

Distribusi jarak septic tank antara air bersih di Dusun Lembang Desa Bonto Biraeng Kecamatan Kajang Kabupaten Bulukumba Tahun 2019

\begin{tabular}{|c|l|c|c|}
\hline No & $\begin{array}{c}\text { Sarana penyediaan air } \\
\text { bersih }\end{array}$ & Jumlah & $\%$ \\
\hline 1 & Memenuhi Syarat & 97 & 73,5 \\
\hline 2 & Tidak memenuhi syarat & 35 & 26,5 \\
\hline & Jumlah & 132 & 100 \\
\hline
\end{tabular}

Tabel 7

Distribusi kondisi sarana jamban keluarga di Dusun Lembang Desa Bonto Biraeng Kecamatan Kajang Kabupaten Bulukumba Tahun 2019

\begin{tabular}{|c|c|c|}
\hline No $\quad$ Kondisjiamban & Jumlah & $\%$ \\
\hline 1 Memennhi Syaratat & 110 & 83,3 \\
\hline 2 Tidar memenenhing syarati & 22 & 16,7 \\
\hline Jumlan & 132 & 100 \\
\hline
\end{tabular}

Tabel 8

Distribusi kondisi sarana pembuangan air limbah di Dusun Lembang Desa Bonto Biraeng Kecamatan Kajang Kabupaten Bulukumba Tahun 2019

\begin{tabular}{|c|c|c|c|}
\hline No & Kondsi pembuangan air limbah & Jumlah & $\%$ \\
\hline 1 & Terouka & 132 & 100 \\
\hline 2 & Tertutup & $\cdot$ & $\cdot$ \\
\hline & Total & 132 & 100 \\
\hline
\end{tabular}

Tabel 9

Distribusi kondisi sarana pembuangan air limbah di Dusun Lembang Desa Bonto Biraeng Kecamatan Kajang Kabupaten Bulukumba Tahun 2019

\begin{tabular}{|c|c|c|}
\hline & aluran pembuluangana air limbah & Jumlah $\%$ \\
\hline & Memenuhi syarat & \\
\hline & Tidak memennhin syarati & $132 \quad 100$ \\
\hline & Jumlah & $132 \quad 100$ \\
\hline
\end{tabular}

Tabel 10

Distribusi ketersediaan sarana pembuangan sampah di Dusun Lembang Desa Bonto Biraeng Kecamatan Kajang Kabupaten Bulukumba Tahun 2019

\begin{tabular}{|c|c|c|c|}
\hline No & Sarana pembuannaan sampanh & Jumlan & $\%$ \\
\hline 1 & Memiliki & 132 & 100 \\
\hline 2 & Tidak memiliki & $\cdot$ & $\cdot$ \\
\hline & Total & 132 & 100 \\
\hline
\end{tabular}


Jurnal Sulolipu : Media Komunikasi Sivitas Akademika dan Masyarakat

Vol. 19 No.2 2019

e-issn : 2622-6960, p-issn : 0854-624X

Tabel 11

Distribusi kondisi sarana pembuangan sampah di Dusun Lembang Desa Bonto Biraeng Kecamatan Kajang Kabupaten Bulukumba Tahun 2019

\begin{tabular}{|c|c|c|c|}
\hline No & Sarana pembuangan sampah & Jumlah & $\%$ \\
\hline 1 & Memenuhi syarat & $\cdot$ & $\cdot$ \\
\hline 2 & Tidak memenuhi syarat & 132 & 100 \\
\hline & Total & 132 & 100 \\
\hline
\end{tabular}

\section{Pembahasan}

Dari hasil penelitian yang dilakukan di Dusun Lembang Desa Bonto Biraeng Kecamatan Kajang Kabupaten Bulukumba responden yang menggunakan sumur gali ada 131 KK $(99,2 \%)$ dan yang menggunakan sumur bor $1 \mathrm{KK}(0,8 \%)$, responden yang memiliki sendiri sumur gali sebanyak 112 rumah $(84,8 \%)$ dan milik tetangga sebanyak 20 rumah $(15,2 \%)$,kondisi sarana penyediaan air bersih di Dusun Lembang sebanyak 97 rumah $(73,5 \%)$ yang memenuhi syarat dan tidak memenuhi syarat sebanyak 35 rumah $(26,5 \%)$ dan yang memiliki sumur bor sebanyak 1 rumah $(0,8 \%)$ memenuhi syarat. Tidak memenuhi syarat di sebabkan karena kondisi pada lantai sumur retak sehingga memungkinkan sumber pencemar meresap cepat kedalam air sumur, dinding sumur yang rata dengan tanah tanpa lantai, dan terdapat sumber pencemaran lain yang dekat dengan sumur gali seperti pembuangan air limbah rumah tangga dan septic tank yang bila tidak memenuhi syarat akan menyebabkan penyakit seperti diare yang disebabkan oleh bakteri E.Coli disebabkan sarana air bersih berdekatan dengan septick tank yang ada. Dan yang memiliki sarana jamban keluarga jenis leher angsa sebanyak $110 \mathrm{KK}(83,3 \%)$, jenis cemplung sebanyak 22 KK (16,7\%), yang memiliki jamban keluarga sendiri sebanyak 132 $\mathrm{KK}$,jamban keluarga yang memenuhi syarat sebanyak $110 \mathrm{KK}(88,3 \%)$ dan $22 \mathrm{KK}$ $(16,7 \%)$ yang tidak memenuhi syarat. Tidak memenuhi syarat di karenakan masih ada masyarakat yang menggunakan jamban cemplung, tidak tertutup sehingga dapat dijangkau oleh serangga terutama lalat, kecoa dan dapat menyebabkan bau.

Sarana jamban keluarga yang tidak memenuhi syarat dapat menjadi tempat perkembangan vektor penyebar penyakit yang bersumber dari tinja yang melalui air dan tangan, yang disebabkan karena cara pembuangan tinja yang tidak saniter.

Kemudian saluran pembuangan air limbah di permukiman Dusun Lembang ini tidak ada yang memenuhi syarat sehingga air tergenang, tidak teratur dihalaman belakang rumah maupun samping rumah. Dan tersedia sarana pembuangan sampah tetapi tidak ada yang memenuhi syarat sebanyak 132 KK (100\%). Tidak memenuhi syarat dikarenakan tidak dipisahkan antara sampah basah dan kering dan pada wadahnya tidak mempunyai penutup.

\section{Kesimpulan}

1. Dari hasil penelitian kondisi sarana penyediaan air bersih di Dusun Lembang Desa Bonto Biraeng Kecamatan Kajang Kabupaten Bulukumba yang memenuhi syarat sebanyak $97 \mathrm{KK}$ (73,5\%) dan tidak memenuhi syarat sebanyak $35 \mathrm{KK}$ $(26,5 \%)$. Dan kondisi sarana jamban keluarga yang memenuhi syarat sebanyak $110 \mathrm{KK}(75 \%)$ yang tidak memenuhi syarat sebanyak $22 \mathrm{KK}$ $(25 \%)$.

2. Kondisi pembuangan air limbah di Dusun Lembang ini sebanyak $132 \mathrm{KK}$ yang tidak memiliki pembuangan air limbah dan tidak memenuhi syarat, dan kondisi sarana pembuangan sampah di dusun Lembang juga tidak ada yang memenuhi syarat sebanyak $132 \mathrm{KK}$.

\section{Saran}

Diharapkan agar kegiatan penyuluhan tentang sanitasi lingkungan lebih ditingkatkan dan dikonsistenkan oleh instansi terkait serta melibatkan masyarakat, mengingat akan masih banyaknya jumlah kasus penyakit yang disebabkan oleh kondisi sarana sanitasi yang tidak memenuhi syarat kesehatan maka perlu diadakan penyuluhan tentang dampak yang ditimbulkan dan penanganannya yang secara terus menerusl dan masyarakat yang hendak membangun rumah agar memperhatikan dan memenuhi ketentuan persyaratan rumah sehat menurut Kepmenkes No.829/Menkes/SK/VII/1999. 
Jurnal Sulolipu : Media Komunikasi Sivitas Akademika dan Masyarakat Vol. 19 No.2 2019

e-issn : 2622-6960, p-issn : 0854-624X 
Jurnal Sulolipu : Media Komunikasi Sivitas Akademika dan Masyarakat

Vol. 19 No.2 2019

e-issn : 2622-6960, p-issn : 0854-624X

\section{Daftar Pustaka}

Adnani Hariza. 2011. Ilmu Kesehatan Lingkungan, Yogyakarta: Gava Media. Chandra Budiman 2005. Pengantar Kesehatan Lingkungan,Kedokteran EGC: Jakarta

Ekapri Tosepu 2017. Gambaran Sarana Sanitasi Masyarakat Di Wilayah Pesisir Teluk Kendari Kelurahan Benua-Benua Kecamatan Kendari Barat Provinsi Tenggara, Kementerian Kesehatan RI Politeknik Kesehatan Kendari jurusan Keperawatan (online), (http://repository.poltekkeskdi.ac.id, diakses 29 Desember 2018).

Inayah,dkk. 2012. Sanitasi Permukiman, Makassar: Tim Penyusun. Mulia Ricki M, 2005. Kesehatan Lingkungan, Yogyakarta: Graha IImu.

Mundiatun, Daryanto, Agung .2015. Pengelolaan Kesehatan Lingkungan, Jakarta: Gava Media.

Notoatmodjo Soekidjo. 2002. Metode Penelitian Kesehatan, Jakarta Pusat: PT Rineka Cipta.

Notoatmodjo Soekidjo .2011. Kesehatan Masyarakat, Deepublish: Yogyakarta. (Online).

(https://books.google.co.id, di akses 29 Desember 2018).

Notoatmodjo Soekidjo. 2010. Promosi Kesehatan: Teori \& Aplikasi. Jakarta: Rineka Cipta.

Pusparani Kahar 2014. Studi Kondisi Sarana Sanitasi Di Desa Pattallikan Kecamatan Manuju Kabupaten Gowa, Makassar Departemen Kesehatan RI Politeknik Kesehatan Makassar jurusan Kesehatan Lingkungan (KTI tidak diterbitkan).

Suyono dan Budiman. 2010. IImu Kesehatan Masyarakat, Jakarta: EGC

Sholehah Imroatus, dkk. 2014. Gambaran Sarana Sanitasi Masyarakat Kawasan Pesisir Pantai Dusun Talaga Desa Kairatu Kecamatan Kairatu Kabupaten Seram Bagian Barat, (Online), Vol. 1, No. 2, (http://journal.uin-alauddin.ac.id, diakses 29 Desember 2018).

Triwibowo Cecep dan Mitha. 2013. Kesehatan Lingkungan dan K3, Yogyakarta: Nuha Medika

WHO.2016.Drinking-water(Online),(http://www.who.int/mediacentre/factsheets/fs330/en, diakses 22 Januari 2019 